\title{
Inverting the Relationship between Development and Public Access Computing (PAC): A Comparative Study of PAC Ecosystems
}

\author{
Caroline Stratton \\ The University of Texas at Austin \\ caroline.stratton@utexas.edu
}

\begin{abstract}
A robust body of research has examined how public access computing (PAC) may support or lead to development in international contexts. This study explores an inverse relationship: how the policy and activity of development shapes PAC. It utilizes the metaphor of the ecosystem to study the ensemble of organizations, resources, venues, and infrastructures that construct and comprise PAC. This study examines $P A C$ ecosystems in two large South American cities, utilizing a case study strategy. Comparison of the PAC ecosystems yields sharp contrasts. The findings indicate that convergences with and divergences from development policy and activity influence the PAC ecosystem, and that studying PAC ecosystems offers a sociotechnical approach to illuminate ICT4D phenomena.
\end{abstract}

Acknowledgements: This research was funded by NSF Grant CHS-1412924.

\section{Introduction}

Proponents of PAC have long claimed that PAC has an important relationship with international development, albeit one that is challenging to articulate [27]. A robust body of research has examined PAC across the world, including users' experiences [2, 13], factors contributing to successful performance of PAC venues [5, 12], and the impacts of PAC use [4, 23]. The simplest relationship drawn between PAC and development is that PAC has the potential to contribute to development because of the value of information [7].

More theoretically-sophisticated research has explored the relationship between PAC and development by incorporating concepts and theories such as social capital $[2,14,28]$ and Sen's capability approach $[17,28]$ to interpret the process by which individuals might achieve gains and what those gains could be. For example, Baron and Gomez [2] interpret
PAC use as a process of empowerment, which may aid individuals in strengthening and establishing interpersonal relationships. Their study reports that users did accumulate social capital, which propagated some effects to users' social networks. Thapa, Sein, and Sæbø find social capital explanations to be compatible with Sen's capability approach, proposing that accumulation of social capital associated with information and communications technology (ICT) use influences collective action and capabilities [28]. Additional theorizing from Kleine [17] proposed how users, encountering specific contexts for ICT access and use and possessing differing levels of capitals (including social) may gain additional choices for their lives as a development outcome.

Examining development resulting from ICT and PAC use does not necessarily exclude other possible relationships between the two phenomena, but it does often overlook the notion that the two might exist in a complex reciprocal relationship. In other words, the phenomenon of development, instantiated in policy and activity, also shapes PAC. Development priorities in a given place may or may not endow PAC with resources. Infrastructure, including electricity and telecommunications systems, may or may not support PAC availability. The existence of venues for PAC, such as libraries, may facilitate or constrain users' opportunities to access and make use of PAC.

In this study, I attend to how development shapes PAC. To study PAC and development, I use the metaphor of the ecosystem to refer to the ensemble of individuals and organizations that furnish and provide PAC, as well as the resources, venues, and infrastructures that comprise PAC. Although other works have utilized the term PAC ecosystem to refer to the venues where PAC is made available, namely libraries, telecenters, and cybercafés [13], I propose redefining the $\mathrm{PAC}$ ecosystem to capture the multitude of actors involved in PAC as well as their relationships. As such, this study is concerned with the interaction of development with the social and organizational relationships, venues, and technical infrastructures that construct and comprise PAC. 


\section{Situating PAC ecosystems and development}

Multiple fields utilize the ecosystem metaphor to organize and interpret phenomena. Organizational ecology, a theoretical orientation within organization studies, examines ecosystems of organizations competing for resources in environmental niches [3]. Many applications of the ecosystem metaphor emphasize social actors: A software ecosystem, for example, refers to actors that interact in a particular software market [6]. Additional social context may also be taken as part of an ecosystem, such as the inclusion of "institutions, social structures and cultural values" in a definition of entrepreneurial ecosystem [25]. There are limited applications of the metaphor that capture social and technical actors in ICT-related contexts (e.g., $[18,21])$; however, such applications have avoided definitional precision.

This study proposes a sociotechnical definition of PAC ecosystem, including individuals, organizations, intangible and tangible resources, venues, and infrastructures. Among the advantages of this definition is that it recognizes the inextricable relationships between people and ICTs, a crucial focus for ICT4D [1]. A social definition of the PAC ecosystem would exclude examination of the spaces, ICTs, and infrastructure that comprise PAC, while a technical definition would exclude examination of people that furnish and utilize PAC. The sociotechnical definition does not privilege either domain as more significant [26].

To investigate how PAC ecosystems demonstrate shaping of development policy and activity further implies the contested concept of development, the multiple associated definitions and theories of which complicate its study [22]. The choice of any particular definition of development influences how development is theorized and observed empirically. For the purposes of this study, I take development at the face value declaration of actors "doing" development. Development policies, for example, state the priorities and outline the activities that governments establish in the name of development, just as development projects and interventions intend to enact some change in the name of development.

By way of background for the empirical study of two PAC ecosystems, the following sections present information about development in the two study countries, including national policies and activities that address the role of ICTs and PAC in development.

\subsection{National context for ICTs and development in Colombia}

Colombia is a country of more than 46 million inhabitants, widely recognized for its problems with narcotrafficking and violence [34]. Colombia strongly embraced neoliberal economic and social policies beginning in the early 1990s [15] and did not stray substantially from such policies through the late 2000s [24]. Despite Colombia's World Bank classification as an upper middle income country, more than $30 \%$ of Colombians live in poverty and the nation receives a significant amount of development assistance [30]. Official development assistance and aid to Colombia from bilateral and multilateral development agencies totaled \$764 million in 2012 [31].

The current development plan for the 2014-2018 period, entitled Todos por un Nuevo País, or "All for a new country," promotes a virtuous circle of development with three pillars of peace, equity, and education [35]. ICTs comprise a small part of the overall plan, but their role in the process of development is to take multiple forms. The plan's general priority, not specific to ICTs, for the region surrounding Medellín, the research site for this study in Colombia, is fostering "innovative human capital in an inclusive territory" [20].

The Colombian government has taken great pride in its accomplishments of extending computer and Internet access to citizens. More than 7600 computer kiosks and 899 digital access points with Internet access have been installed across the country, under an initiative, Plan Vive Digital, which served as the primary ICT access policy from 2010-2014 [19]. The ICT Ministry celebrated its accomplishments under Plan Vive Digital, "the world's best ICT policy." [37]. A new Plan Vive Digital 2 will guide the ministry's ICT activities through 2018. Plan Vive Digital 2 organizes goals under the rubrics of applications (i.e., Internet and computer apps), users, services, and infrastructure [36]. Plan Vive Digital 2 establishes the goal of connecting 27 million Colombians to the Internet.

In 2014, $46 \%$ of all Colombians had access at home to a computer and $42 \%$ had Internet access at home, rates of which rise to $53 \%$ and $56 \%$, respectively, when including access at work [39]. Cellphone use was more prevalent: $82.9 \%$ of Colombians utilized them in 2014 [39].

\subsection{National context for ICTs and development in Bolivia}

The nation of Bolivia has about 10.6 million inhabitants [34] and has generated attention during the last decade for its rejection of neoliberalism and turn to the left end of the political spectrum [11]. The political party in control of national government, Movimiento al 
Socialismo (MAS) or Movement Towards Socialism, embraced social movements of indigenous people, rural people, urban workers, coca farmers, miners, and other groups under a single banner [11]. Bolivia is among the least developed nations in South America, but it has enjoyed recent economic growth. Bolivia received $\$ 658$ million in official development assistance and aid [31].

Of the four pillars in Bolivia's national development plan, ICTs have a designated role in two, dignity and productivity [33]. Within dignity, ICTs are part of the planned strategy for education, in that statedonated computers will allow teachers and students to access information "to widen their worldview" [33]. Within the pillar of productivity, goals for productive telecommunications include a universal service program to install 2000 telecenters, 8500 public telephones, and 1500 radio transmission stations.

ICT policy in Bolivia lacks a single guiding plan or even a single agency that oversees ICT activity. A variety of government bodies address aspects of ICT policy, including the Vice Ministry for Science and Technology, which supports school telecenters and the one laptop per teacher program; the Agency for Development of the Information Society in Bolivia, which supports e-government and general use of ICTs in government; the Ministry of Education, which supports pedagogy and ICTs as well as teacher training in ICTs; and the Ministry of Productive Development and the Plural Economy, which oversees Quipus, the state-run computer assembly company.

Just $28 \%$ of the population in Bolivia had home access to a computer and $14 \%$ had Internet access at home through a computer in 2014 [39]. When rates of access include the workplace, $36 \%$ of Bolivians used computers and $35 \%$ of Bolivians used the Internet in 2014. The rate of cellphone use was $70.3 \%$ in 2014 [39].

\section{Methods}

I constructed two case studies about the PAC ecosystems of Medellín, Colombia and Santa Cruz de la Sierra, Bolivia. Both are "second cities," large, important metropolises that are not country capitals. This study employs a comparative case study strategy, appropriate for use in research when context must be explored to understand a phenomenon, given that "the boundaries between phenomenon and context may not be clearly evident" [16]. I employed the case study strategy because the boundaries of the PAC ecosystem were not known prior to empirical study.

Within the case study strategy, I utilized multiple methods of data collection, specifically semistructured interviews, ethnographic observation, and document review, allowing for triangulation of data. I collected data for three months each in Colombia and Bolivia during 2015. This study draws upon 50 semistructured interviews [29], lasting between 30 minutes and two hours, and 80 ethnographic observations [10]. Theoretical sampling guided the selection of observation sites and interview informants [8]. Specifically, to investigate how development policy and activity shaped PAC ecosystems, I selected informants with knowledge of and experience in local development activity and the PAC ecosystem. Interview informants included government officials responsible for PAC programs and infrastructure, representatives of civil society organizations that furnish and utilize PAC, librarians, educators, and other individuals participating actively in the PAC ecosystem. In accordance with theoretical sampling procedures, the cumulative insights of interviews and observations influenced subsequent data collection. Study participants provided informed consent for participation according to university IRB requirements. In both cases, I gained initial access through civil society organizations. Key informants with experience in the PAC ecosystem within those organizations provided introduction to additional organizations and informants.

The case studies address free PAC (thereby excluding venues and actors related to cybercafés). All interviews were conducted in Spanish, then transcribed from an audio recording and translated. Ethnographic observation of PAC ecosystems took place primarily in libraries and telecenters. Document review of national and local ICT policies supplemented the data I collected to add context to the workings of the ecosystem. Rather than understanding context and culture as entities to be discovered, this study takes a generative view [16]: actors in the PAC ecosystem dynamically and collectively generate context and culture through their interactions.

Processes of data collection and analysis were simultaneous; I utilized multiple preliminary analysis techniques to organize data, develop themes, and determine next steps throughout data collection. Through these processes, the data reached theoretical saturation when data collection did not reveal new insights and themes [8]. I utilized iterative, qualitative coding to analyze the data. In particular, coding attended to informants' talk and action about events that established and shaped the PAC ecosystem, such as donations of equipment and establishment of venues. I also coded for informants' perceptions of physical aspects of PAC, such as the quality of venues and infrastructures, as well as their perceptions of organizational aspects of PAC ecosystem. Following a within-case analysis of themes, I conducted a between- 
case analysis to compare the most prominent features of the data about the PAC ecosystems.

Multiple strategies in the research design contribute to the validity of the study. Triangulation of data collection methods and prolonged engagement in the field enhanced validity [9]. I conducted member checking with key informants to test early analyses, also bolstering construct validity [9, 32]. The comparative case study design additionally supports external validity [32].

\section{Findings}

This section presents themes from the cases of the PAC ecosystems of Medellín and Santa Cruz de la Sierra (hereafter, shortened to Santa Cruz).

\subsection{The PAC ecosystem in Medellín}

A first prominent theme that emerged about the PAC ecosystem in Medellín was a perception that traditional PAC venues and programs were of high quality and enjoyed strong municipal support. Libraries and telecenters had received devices from multiple organizations, such that computers were abundant. The local utility group in Medellín, through its charitable foundation and its telecommunications company, had donated computers and connectivity to public libraries. Julian, the digital culture coordinator at a large library park, explained that not only had a subsequent award provided additional devices to the libraries but that it had also given momentum to a citywide emphasis on ICTs:

The technology aspect has been very, very strong [in the library] because after one or two years of operation, the Bill and Melinda Gates Foundation recognized us [the library system] with global prizes and the Network of Public Libraries of Medellin with an important award, so we started to emphasize the theme of technology in Medellin, all the municipal policies about technology.

Municipal support for libraries and PAC even appeared stable enough to transcend political influences, such as changes in administration. Diego, the digital culture coordinator for the entire Public Library System, reflected on the reasons why libraries enjoyed strong municipal support:

What people that have been working in the [library] system for many years say is that the libraries are more or less stable. . . The libraries, and we say this as a criticism, are part of the marketing of the city. If you look in a tourist guide you can see in one section, "places of interest, library parks." Precisely because of that in one of our working groups, we asked ourselves, "Why were library parks created? A political strategy? Or did they come from a citizen movement that demanded them?" . . . For whatever reason, the last three governments have created these library parks and from these three governments there has been continuity in support for culture. These governments have fomented the development of the city through these cultural strategies.

In addition to the stable political footing of libraries and PAC more generally in Medellín, informants perceived PAC locations in Medellín as exemplars, suitable for emulation in other cities and countries.

Diana, the director of a local NGO with a history of work in libraries and telecenters, prepared a presentation to deliver in Panama about PAC in Medellín that made clear how her organization perceived telecenters in Medellín as well-run venues offering important services beyond simple access to ICT. In a meeting with her staff to finalize her presentation, Diana explained to them that infoplazas in Panama (the local term for telecenters) were like telecenters of the past in Medellín. This excerpt from fieldnotes documents the meeting:

Diana reads a text from the director [of the event].

He wants her to talk about access. "We've resolved the problem of access," the text says, but now the infoplazas should be a space for encounter. She says that if you ask infoplazas what services they provide they will say things like "internet and photocopying." She says infoplazas in Panama are like telecenters here [in Medellin] 10 years ago, they just provide access.

During the meeting, members of the NGO staff went on to suggest that Diana speak about the success of telecenters in Medellín. Tania, an ICT facilitator with extensive work experience in PAC, emphasized a model of financial sustainability and changes in PAC priorities:

Tania mentions telecenters in Medellin that are self-sustaining. She continues to say that telecenters make alliances with other entities and offer services in the community that result in their financial sustainability . . . Tania adds that libraries and telecenters in Medellin are reducing space for free computer use right now. They are trying to increase training spaces. They keep some time open for free computer use but it is not as much "as when people didn't have computers at home."

Tania's implication that people in Medellín now have computers at home echoed another finding from the Colombia case, that many people in Medellín had access to ICTs through personal ownership. Personal ownership of ICTs, combined with high quality 
traditional PAC venues, allowed actors to experiment with PAC in new forms and spaces.

Thus, a second prominent theme from the Medellín case was that the PAC ecosystem extended beyond traditional venues for $P A C$, incorporating additional spaces and implicating new actors. An entity within the city government, the City Digitization Department (CDD), had established hundreds of zones offering free WiFi connectivity in public spaces throughout Medellín. Funding for the initiative came from the highly profitable municipal utility group, which had recently sold a portion of its telecommunications company to a foreign buyer. With these funds, CDD created the zones so people would leverage the connectivity for beneficial information and communication processes. David, a communications manager for the CDD explained that although some changes had occurred in the department's nine-year history, its goal remained to provide Internet connectivity to everyone in Medellín:

Yes, so the City Digitization Department was started in the year 2008. Medellin needed to begin getting serious about Internet. It's not some distraction for kids, it's not something that is just used for amusement. It's actually something that we can work on . . . . In 2011 we went to Digital Opportunities NGO and we asked them to make a new strategy for us. We wanted to know what was the next step . . . Some of the original objectives of the City Digitization Department haven't been achieved yet because all of the people of Medellin do not yet have connectivity. Pretty much no country in the world has that, but it's still our aim. We are not quitting on that.

David went on to explain that CDD's work to provide WiFi near several busy Medellín Metro stations and parks in 2015 had come under fire. Some of the spaces featured high potential for theft of cellphones and other personal articles. Despite the potential, people did utilize these higher risk WiFi zones and CDD sought them out to demonstrate to others how to make safe use of the zones. David spoke about the higher risk WiFi zones:

This year we have connected a lot of places in downtown Medellin. We received a lot of criticism because of safety issues. People say, "No one's going to use them [WiFi zones]. No one's going to pull out their cellphones in downtown." But it turns out that among the zones with the most users, seven or eight of them are in downtown because that's where the people are. I know it isn't safe, but we just posted an article about it on our website. We went to the downtown zones and took pictures of people actually using their cellphones and WiFi. They were giving us advice like, "You can stand next to the police and you know nothing's going to happen to you." That's a good start.

CDD's work also included furnishing PAC for specific functions, such as paying bills in government offices. The organization set up computing kiosks, often designed for use while standing, to encourage brief sessions of use.

The placement of kiosks outside traditional PAC spaces, such as the WiFi zones in parks, had some unexpected consequences, particularly because it was difficult to monitor the use of such locations. In contrast with the example of the police presence providing safety for PAC users, CDD became aware of a scam consisting of individuals misappropriating the PAC kiosks in transportation hubs and charging others for use. I documented Cristina, the appropriation manager at CDD, explaining the problem in my fieldnotes:

Cristina mentions that she started a new program yesterday with the Secretary of Mobility in Medellin. She tells us that there are individuals taking advantage of the kiosks in the city to make money off of citizens. Use of the kiosks is intended to be free, but these people set up in very busy areas and ask for money to help people complete online transactions. They operate from kiosk points that are very chaotic and they charge people 30000 pesos for their service. Cristina says they are working on an information campaign so that people know they don't have to pay these intermediaries and so they know how to complete transactions on their own. Cristina remarks that it is a shame these people are taking advantage of a public service, provided by the government.

The provision of PAC in nontraditional spaces, as well as CDD and the Secretary of Mobility's efforts to follow up on misuse of PAC indicate cooperation and commitment across government entities related to PAC.

In sum, the data regarding the Medellín PAC ecosystem show its infrastructural members to be diverse. The infrastructure includes traditional and nontraditional venues for PAC, as well as WiFi networks that leverage personal ownership of ICTs by people in Medellín. Examining the social and organizational members of the ecosystem, local government in Medellín took PAC seriously as a commitment to its citizens. The expected organizational actors such as government, telecommunications companies, and NGOs, participated in the PAC ecosystem, in addition to unexpected actors such as police and scammers that emerged adjacent to infrastructure. 


\subsection{The PAC ecosystem in Santa Cruz de la Sierra}

The PAC ecosystem of Santa Cruz presented strong themes that were quite different from those in the previous case. The most prominent finding in Santa Cruz was the near absence of traditional PAC venues and utter lack of resources. As I sought out libraries and telecenters presenting free PAC, I found few locations, highly limited quantities of ICTs, and minimal availability for public access.

The only PAC venues associated with local government in Santa Cruz were public libraries. The central municipal library, the largest of its kind in a city of about 1.5 million inhabitants, had just six PCs available for public use. The director of the library, Samuel, explained that the lack of government support for $\mathrm{PAC}$, specifically $\mathrm{WiFi}$, was embarrassing given the financial resources of the city and previous campaign promises.

This is one of the most important cities in the country, and it has enough resources to have a good library network. That's why I'm embarrassed to beg for internet access despite being in one of the richest cities, when they [the government] can easily pay for it and offer it to the citizens. However, that's the reality of the situation. In a way, we [the citizens] allow them to wash their hands from the responsibility of providing this access to the citizens. In fact, I think they [the administration] used it as a campaign promise on two occasions. They offered WiFi in the libraries or in the schools, but that didn't end up happening.

Local government had been concerned lately with building new, additional facilities such as schools and libraries, rather than equipping the facilities with ICTs and connectivity. Samuel traced the lack of support for PAC to high-level officials in the city and the political risk that supporting PAC might present. He spoke about how PAC in the library might enhance government services and leverage the existing infrastructure:

Maybe the administration will realize they can solve problems, such as [citizens] paying taxes at the library. The library shouldn't just be for taking out books, but for helping citizens in other matters. But you're always struggling with a high-level official, and they don't always agree when it comes to making a political decision. And they even consider it a risk. Regrettably, that's how it works here. I'm hopeful that at some point a high-level official will realize we can offer citizens several things with this infrastructure [the libraries] that is spread all over the city. It could even be a source of revenue.
With the lack of financial and political support for PAC from local government, the library had turned to the private sector for Internet connectivity. In doing so, the library worked with the charitable foundation of a private telecommunications company, VIVA. The presence of VIVA is notable in Bolivia, because among its competitors is the nationalized, state-run telecommunications company, Entel.

Other venues in the PAC ecosystem in Santa Cruz were furnished by NGOs. NGO-run telecenters offered access to computers, Internet, and training courses, directed mainly to their client populations. Women's Foundation, an NGO working to reduce the incidence of domestic violence and work with survivors, had a small, ten-computer telecenter in its main office in Santa Cruz. Marina, a lawyer with Women's Foundation, suggested that the telecenter was important because of a lack of Internet access rather than device ownership, even though rates of access to computers at home were quite low:

That is why we create info-centers, like this one: it is where we teach them [users] to access a computer because not everyone in Bolivia has Internet access ... So these programs are mostly targeted to young women, but the idea is that we give them intensive and basic classes about computing and Internet access.

Marina's remarks also reveal that knowledge of basic computer skills may be uncommon for clients of her NGO, such that they would need training to make use of a PAC venue. When I visited the Women's Foundation telecenter, it was not in regular operation. The need to employ trainers and a lack of resources to do so was among the reasons that Marina provided for why the telecenter was not working.

Right now the info-center is not operating, the classes taught there are not currently working... it's just that right now all NGOs are without money. We do not have any money, and the problem is who will teach the courses to women? We were working up until two months ago with students from the university who were on vacation. We had space and time available, but they only came twice a week.

The financial situation of NGOs that Marina referred to relates to both a general lack of financial support for NGOs in Bolivia due to an unfriendly climate for foreign support, as well as the specific departure of a European NGO that aided Bolivian organizations working with ICT4D initiatives. In general, public sector and civil society organizations trying to sustain PAC found themselves working with minimal quantities of equipment and professional labor, while relying on some volunteer labor and charitable donations to make PAC available. 
The faltering state of the PAC ecosystem in Santa Cruz, when compared to the national government discourse about ICTs and technological development, leads to another theme from the data: that the national government had priorities for technology development and diffusion that bypassed and constrained the PAC ecosystem.

First, prioritizing the diffusion of ICTs through the public education system bypassed the traditional PAC venues of libraries and telecenters open to all. The government focused heavily on computing in education, spending its resources on providing laptops to teachers and students. Earlier government programs had established so-called telecenters in schools, which were typically used as computer classrooms, only open to students during the day during a computer skills class. A minority of schools had attempted to open their telecenters to the public, but most lacked Internet connectivity and paying the computer teacher to stay for additional time to monitor the telecenter could be costly. In an excerpt from my fieldnotes, Lupita and Henry, the vice principal and telecenter teacher, respectively, at a public school explained to an $\mathrm{NGO}$ worker, Paula, that even when the telecenter was open, students did not use it for PAC:

Lupita says that Henry works all morning and that he has drop-in hours in the afternoon, but they are basically free time for Henry because no one comes in.

Lupita: No one comes in to use the Internet.

Henry: They all use their cellphones!

Paula: Then do kids come in to do research projects, work on homework?

Lupita and Henry say no.

In other words, educational computing facilities rarely provided PAC to the community and not even pupils used the facilities outside of class. The distribution of laptops to public school students also did not expand ICT diffusion in the community, for example, to the students' family members, because the laptops were intended solely for use at school and were not to be brought home. Thus, national expenditures on educational computing had little to no influence on the PAC ecosystem, other than to bypass it.

Second, the national government's lack of priority for upgrading Internet infrastructure constrained connectivity in the PAC ecosystem and made expansion of connectivity an unattractive pursuit. Bolivia boasts some of the slowest and most expensive Internet service in South America [38], due in part to its lack of digital subscriber line (DSL) coverage and overemphasis on mobile technology. Teodoro, a leader of a group of Internet activists in Bolivia described the problem with Internet infrastructure:
Here in Bolivia, Internet consumption has always been oriented towards mobile technology. We have skipped the cabled infrastructure. It's much cheaper for the mobsters to put up an antenna and say, "I give you coverage". The minimal infrastructure there was of ADSL cabling was actually intended for businesses. It was a service conceived for corporations. A corporate privilege. It was sold as if the cable was made of gold and not copper. It had a ridiculous speed of 128 kilobytes per second. The people who boasted of having a great connection actually had 128 or 256 kilobytes per second. They were calling that broadband. Even now, to call it broadband with two megabytes is pretty questionable.

The fact that mobile Internet service was slow also shaped the PAC ecosystem and how users leveraged PAC. As previously described, Santa Cruz had very little free PAC, but it did have numerous cybercafés. Raúl, another Internet activist suggested that children using cybercafés chose not to explore the full range of activities available to them on the Internet because of speed and cost:

Kids don't have many [financial] resources. When they got an internet cafe to go online, they have to maximize their benefit and minimize their costs. So, the only thing they can do is use Facebook. They don't do research or other things. The synonym of expensive is scant. If you can't pay much, then you'll receive less. If you want fast internet access, you have to pay a lot.

Costly Internet access and a prepay for data model for personal device use and cybercafé minutes not only affected consumers, but free PAC venues as well. Samuel, the library director in Santa Cruz, told me that when Internet signal went down in the library, it could be because the library's credit (based on data consumption) had run out:

In this building, for example, there is WiFi, supposedly. But it fails here. The signal is not good. It goes down. We do not know if it is our fault, by not reporting it to VIVA, or if the credit is gone.

Thus, the bad state of Internet infrastructure, a national problem, constrained the PAC ecosystem in Santa Cruz. Adding more computers at the central municipal library, for example, could potentially worsen Internet speeds and deplete data allowances more quickly. Government promises to upgrade infrastructure and install fiber optic cable went unfulfilled at the time of data collection in 2015. At that time, the state telecommunications company, Entel, had projects in progress to connect schools to the Internet, again bypassing the PAC ecosystem.

Taken together, the data from the Santa Cruz case illustrate a weak PAC ecosystem lacking strong 
financial or political support, but also hampered by the national priority for educational computing and poor Internet infrastructure.

The themes characterizing each PAC ecosystem in the preceding section present stark contrasts: Medellín appeared to have a vibrant, diverse PAC ecosystem, while the PAC ecosystem in Santa Cruz appeared resource-starved and without strong support. For comparison, Table 1 lists features of the two PAC ecosystems, according to their key participants, resources, venues, and infrastructure.

Table 1. Comparison of the PAC ecosystems

\begin{tabular}{|l|l|l|}
\hline & Medellín & Santa Cruz \\
\hline Pey & $\begin{array}{l}\text { Municipal } \\
\text { government } \\
\text { entities, NGOs, } \\
\text { library system, } \\
\text { public utility } \\
\text { group, privatized } \\
\text { telecom }\end{array}$ & $\begin{array}{l}\text { Library system, } \\
\text { NGOs, private } \\
\text { telecom, } \\
\text { volunteers }\end{array}$ \\
\hline Resources & $\begin{array}{l}\text { Multiple sources } \\
\text { of political and } \\
\text { financial support }\end{array}$ & $\begin{array}{l}\text { Little to no } \\
\text { political support, } \\
\text { coupled with little } \\
\text { to no financial } \\
\text { support }\end{array}$ \\
\hline Venues & $\begin{array}{l}\text { Libraries and } \\
\text { telecenters, plus } \\
\text { public WiFi } \\
\text { zones and kiosks }\end{array}$ & $\begin{array}{l}\text { Libraries and } \\
\text { NGO-furnished } \\
\text { telecenters }\end{array}$ \\
\hline Infrastructure & $\begin{array}{l}\text { Extensive public } \\
\text { infrastructure, } \\
\text { plus WiFi } \\
\text { infrastructure to } \\
\text { leverage private } \\
\text { ownership of } \\
\text { devices }\end{array}$ & $\begin{array}{l}\text { Limited } \\
\text { availability and } \\
\text { access to } \\
\text { computers, slow } \\
\text { and expensive } \\
\text { Internet }\end{array}$ \\
\hline
\end{tabular}

\section{Discussion}

The preceding findings indicate convergences of development policy and activity that support and create a positive feedback loop for the PAC ecosystem in Medellín, as well as divergences of development policy and activity that constrain the PAC ecosystem in Santa Cruz. Inspired by the comparison of cases, this section draws out three contributions and implications for the study of PAC and ICT4D more generally.

First, the sociotechnical definition of the PAC ecosystem allows for simultaneous consideration of social actors and technological artifacts. Investigating the relationship of development policy and activity and the PAC ecosystem with a social lens would bring to the fore the ways in which local, national, and international development foci impacted actors in social, political, and financial senses, for example. Utilizing a technical lens would highlight the role of development policy and activity in furnishing particular systems, devices, and infrastructure. By integrating the social and technical, this study illuminates individuals' and organizations' interactions with ICTs in the context of PAC. Investigating individual and organizational practices with ICTs, a cornerstone of sociotechnical research [26], uncovered unexpected interactions, such as the scammers charging others to use free PAC on their behalf in Medellín, or that children in Bolivia preferred using mobile phones to desktop computers with an Internet connection at school. Such interactions point to the limitations of purely social or technical explanations for the outcomes of ICT introduction.

Examining the PAC ecosystem also indicates how participants might increase access, coverage, and services effectively: Given the limited political and financial support for the PAC ecosystem in Bolivia and the lack of cabled Internet infrastructure, strategies to leverage individuals' access to mobile phones, provide WiFi in public places, and develop lightweight local content may prove more impactful than seeking scant resources to purchase desktop computers.

Second, applying the metaphor of ecosystem to other sectors and areas of ICT4D study may be fruitful for scholars. The components of the PAC ecosystem, such as key participants, resources, venues, and infrastructure are present in other domains, such as agriculture, education, and health. Identifying and investigating the constituent components of an ecosystem has several potential uses. To technologists, practitioners, and interventionist ICT4D scholars, tracing an ecosystem may indicate a particular course of action, such as specific organizational relationships and technologies to utilize and leverage. To scholars seeking to explain how an intervention proceeded, the ecosystem offers a generative approach to context [16] and a sociotechnical perspective to study outcomes. The ecosystem, applied to ICT4D activity, may also illuminate social and technical strengths and weaknesses in particular locations that enable or constrain success.

Third, this study suggests several directions to further relate PAC and development. Organizational relationships in the PAC ecosystem indicated a role for social and other types of capital, in which organizational actors held or lacked adequate capital to obtain resources, furnish, and support PAC venues. Thus, organizations' (and their leaders') capital influenced the provision of ICTs for PAC users to subsequently develop their own capital and capabilities through use of ICTs. The role of organizational 
relationships and capital also suggests that theories of collective action may be useful for interpreting how actors organize and unite to promote PAC as well as ICT4D.

\section{Conclusion}

This study has inverted a relationship that links PAC use with development impact, instead examining how processes of development, as represented by policy and activity, shape the PAC ecosystem in a given place. The inverted logic is complementary to research about the impact of PAC, as it may aid researchers in situating their results about the development impact of PAC use. In particular, understanding how development shapes PAC can illuminate situations in which users do or do not achieve development benefits from PAC by adding essential context. The metaphor of the PAC ecosystem suggests empirical study of the conditions surrounding PAC, which may provide greater insight into topics that persist in PAC research, such as venue performance and sustainability, as well as inspiration for theorizing these topics. This study stops short of studying users and their experiences in the PAC ecosystems. As a next step, integrated study of a PAC ecosystem and PAC use can present a more holistic understanding of PAC and development.

\section{References}

[1] Avgerou, C. Discourses on ICT and Development. Information Technologies \& International Development 6, 3 (2010), 1-18.

[2] Baron, L.F. and R. Gomez. Relationships and connectedness: Weak ties that help social inclusion through public access computing. Information Technology for Development 19, 4 (2013), 271-295.

[3] Baum, J.A.C. and A.V. Shipilov. Ecological Approaches to Organizations. In S.R. Clegg, C. Hardy and T.B. Lawrence, eds., SAGE Handbook of Organization Studies. SAGE Publications Ltd., London, 2006, 55-110.

[4] Becker, S., M.D., Crandall, and K.E. Fisher. Communicating the Impact of Free Access to Computers and the Internet in Public Libraries: A Mixed Methods Approach to Developing Outcome Indicators. Public Library Quarterly 28, 2 (2009), 109-119.

[5] Bertot, J.C. and D.M. Davis. Public Library Public Access Computing and Internet Access: Factors Which Contribute to Quality Services and Resources. Public Library Quarterly 25, 1-2 (2006), 27-42.
[6] Boucharas, V., S., Jansen, and Brinkkemper, S. Formalizing Software Ecosystem Modeling. Proceedings of the 1st International Workshop on Open Component Ecosystems, ACM (2009), 41-50.

[7] Colle, R. Communication shops and telecenters in developing nations. In M. Gurstein, ed., Community informatics: Enabling communities with information and communications technologies. IGI Global, Hershey, PA, $2000,415-445$.

[8] Corbin, J. and A. Strauss. Basics of qualitative research: Techniques and procedures for developing grounded theory. SAGE, Thousand Oaks, CA, 2008.

[9] Creswell, J.W. and D.L. Miller. Determining Validity in Qualitative Inquiry. Theory Into Practice 39, 3 (2000), 124130 .

[10] Emerson, R., R. Fretz, and L. Shaw. Writing ethnographic fieldnotes. University of Chicago Press, Chicago, IL, 1995.

[11] Farthing, L. and B. Kohl. Evo's Bolivia: Continuity and change. University of Texas Press, Austin, TX, 2014.

[12] Gomez, R. Success factors in public access computing for development. In S. Chhabra, ed., ICT Influences on Human Development, Interaction, and Collaboration. IGI Global, Hershey, PA, 2013, 97-184.

[13] Gomez, R. When You Do Not Have a Computer: Public-Access Computing in Developing Countries. Information Technology for Development 20, 3 (2014), 274291.

[14] Gomez, R., P. Reed, and H.Y. Chae. Assessment of Community Wellness Outcomes to Measure ICT Impact. Proceedings of the Sixth International Conference on Information and Communications Technologies and Development: Notes - Volume 2, ACM (2013), 37-40.

[15] Gow, D. "En minga por el Cauca": Alternative government in Colombia, 2001-2003. In M. Goodale and N. Postero, eds., Neoliberalism, interrupted: Social change and contested governance in contemporary Latin America. Stanford University Press, Palo Alto, CA, 2013, 75-108.

[16] Irani, L., J. Vertesi, P. Dourish, K. Philip, and R.E. Grinter. Postcolonial Computing: A Lens on Design and Development. Proceedings of the SIGCHI Conference on Human Factors in Computing Systems, ACM (2010), 13111320.

[17] Kleine, D. Technologies of Choice?: ICTs, Development, and the Capabilities Approach. MIT Press, 2013. 
[18] Kumar, N. and N. Rangaswamy. The Mobile Media Actor-network in Urban India. Proceedings of the SIGCHI Conference on Human Factors in Computing Systems, ACM (2013), 1989-1998.

[19] Leosil. Internet.org llega al país de la mano de Facebook: Colombia es el primer país del continente y el cuarto del mundo en adoptar esta iniciativa, después de Indonesia, Tanzania y Kenia. El Tiempo; Bogotá, 2015.

[20] Marmor. 'Todos por un nuevo país', el plan 20142018: Tras una demora por ajustes finales, hoy se presentarán las bases del Plan de Desarrollo del cuatrienio. El Tiempo; Bogotá, 2014.

[21] O’Neill, J., A. Dhareshwar, and S.H. Muralidhar. Working Digital Money into a Cash Economy: The Collaborative Work of Loan Payment. Computer Supported Cooperative Work (CSCW) 26, 4-6 (2017), 733-768.

[22] Peet, R. and E. Hartwick. Theories of development: Contentions, arguments, alternatives. Guilford Press, New York, NY, 2009.

[23] Proenza, F., ed. Public access ICT across cultures: Diversifying participation in the network society. MIT Press, Cambridge, MA, 2015.

[24] Rojas, C. Colombia's neoliberal regime of governance: Securitization by dispossession. In L. Macdonald and A. Ruckert, eds., Post-neoliberalism in the Americas. Palgrave Macmillan, New York, NY, 2009, 231-245.

[25] Roundy, P.T. Start-up Community Narratives: The Discursive Construction of Entrepreneurial Ecosystems. The Journal of Entrepreneurship 25, 2 (2016), 232-248.

[26] Sawyer, S. and M. Jarrahi. The Sociotechnical Perspective. In A. Tucker and H. Topi, eds., CRC Handbook of Computing. Chapman and Hall, New York, 2014, 5-1-527.

[27] Sey, A. Public access to ICTs : a review of the literature. Center for Information and Society, University of Washington, Seattle, WA, US, 2008.

[28] Thapa, D., M. Sein, and Ø Saebø. Building collective capabilities through ICT in a mountain region of Nepal: where social capital leads to collective action. Information Technology for Development 18, 1 (2012), 5-22.
[29] Weiss, R. Learning from strangers: The art and method of qualitative interview studies. The Free Press, New York, NY, 2011.

[30] World Bank. Colombia: World development indicators. http://data.worldbank.org/country/colombia\#cp_gep.

[31] World Bank. Net official development assistance and official aid received (current US\$) (indicator). http://data.worldbank.org/indicator/DT.ODA.ALLD.CD/cou ntries.

[32] Yin, R. Case study research: Design and methods. SAGE, Thousand Oaks, CA, 2014.

[33] Plan Nacional de Desarrollo. 2006. Estado Plurinacional de Bolivia. Ministerio de Planificación del Desarrollo.

[34] The World Factbook 2013-2014. Central Intelligence Agency, Washington, DC, 2013.

[35] Bases del Plan Nacional de Desarrollo 2014-2018: Versión Preliminar para Discusión del Consejo Nacional de Planeación. Departamento Nacional de Planeación [República de Colombia]. 2014.

https://colaboracion.dnp.gov.co/cdt/prensa/bases\%20plan\%2 0nacional\%20de\%20desarrollo\%202014-2018.pdf

[36] El Presidente Santos presentó el Plan Vive Digital 20142018 en ANDICOM 2014. Ministerio de Tecnologías de la Información y las Comunicaciones de Colombia. 2014. http://www.mintic.gov.co/portal/604/w3-article-7080.html

[37] Logros del gobierno Santos en tecnología. Ministerio de Ministerio de Tecnologías de la Información y las Comunicaciones de Colombia. 2015. http://www.mintic.gov.co/portal/604/articles5193_logros_sept_2015.pdf.

[38] Las conexiones de internet más rápidas y más lentas de América Latina. BBC Mundo, 2015.

http://www.bbc.com/mundo/noticias/2015/08/150819_difusi on_internet_america_latina_cepal_ac.

[39] Statistics: World Telecommunication/ICT Indicators Database. International Telecommunication Union, 2017. http://www.itu.int:80/en/ITU-

D/Statistics/Pages/stat/default.aspx. 